\title{
Evaluation of the maxillary midline, curve of the upper lip, smile line and tooth shape: a prospective study of 140 Caucasian patients
}

\author{
María Melo ${ }^{1,2} \mathbb{D}$, Javier Ata-Ali $2,3,4^{*} \mathbb{B}$, Fadi Ata-Ali ${ }^{4}$, Marco Bulsei ${ }^{2}$, Perluigi Grella ${ }^{2}$, Teresa Cobo ${ }^{4}$ and
} José María Martínez-González ${ }^{5}$ (D)

\begin{abstract}
Background: A number of reference patterns such as the interincisal line, curve of the upper lip, width of the smile or shape of the teeth have been studied in different populations. Determining the frequency of different smile aesthetic parameters in a European Caucasian population and exploring possible gender differences is important in order to obtain predictable treatment outcomes.

Methods: Photographs were obtained under resting and forced smiling conditions in 140 individuals (70 males and 70 females) with a mean age of $20.1 \pm 4.3$ years. Different variables were recorded, including the position of the maxillary interincisal midline in relation to the facial midline, the arc and width of the smile, and the shape of the teeth. The data were processed using the SPSS version 15.0 statistical package, with application of the chi-squared test and a confidence level of $95 \%$. The statistical power was $80 \%$, and the level of significance $5 \%(a=0.05)$.

Results: A total of $94.3 \%$ of the sample presented a maxillary interincisal midline coinciding with the facial midline, and $80 \%$ had a consonant smile line. The curve of the upper lip was upwards in $47.1 \%$ of the cases, followed by a straight curve in $41.4 \%$. Most of the subjects (84.3\%) presented a medium smile line with tooth exposure to the second premolar (61.4\%). There were no significant differences between males and females.

Conclusions: The integration of aesthetic criteria is needed in order to guarantee satisfactory and predictable dental treatment outcomes. There were no statistically significant differences between males and females. The maxillary interincisal midline coincided with the facial midline, with a consonant smile arc and a medium smile line, upward lip curve and oval tooth shape.
\end{abstract}

Keywords: Smile line, Dental aesthetics, Tooth shape, Dental midline, Facial aesthetics

\section{Background}

The ideal characteristics of a smile have been described by different authors $[1,2]$, though deviations from the classical aesthetic dimensions are found in the different studied populations [3-5]. Different methods are available for analysis of the smile, including photographs $[6,7]$, videos $[8,9]$

\footnotetext{
* Correspondence: javiataali@hotmail.com

${ }^{2}$ Department of Dentistry, Universidad Europea de Valencia. Faculty of Health Sciences, Valencia, Spain

${ }^{3}$ Dentist, Public Dental Health Service, Conselleria de Sanitat Universal i Salut Pública, Generalitat Valenciana, Valencia, Spain

Full list of author information is available at the end of the article
}

or the use of three-dimensional (3D) stereophotogrammetric images [10].

There are two types of smile: spontaneous and forced. The former is involuntary, with elevation of the lip induced by happiness, and can be taken to express genuine emotion [11]. Elevation of the lip is greater than in the case of a posed smile [12], which is reproducible and thus involves a reference position [13]. In facial analysis we have a number of horizontal reference lines (the bipupillary line and other lines parallel to the latter) and the vertical midline located by two anatomical reference points: the nasion and the filtrum [6]. The more perpendicular this line is to the

(c) The Author(s). 2020 Open Access This article is distributed under the terms of the Creative Commons Attribution 4.0 International License (http://creativecommons.org/licenses/by/4.0/), which permits unrestricted use, distribution, and reproduction in any medium, provided you give appropriate credit to the original author(s) and the source, provide a link to the Creative Commons license, and indicate if changes were made. The Creative Commons Public Domain Dedication waiver (http://creativecommons.org/publicdomain/zero/1.0/) applies to the data made available in this article, unless otherwise stated. 
bipupillary line, the greater the sensation of total harmony of the face [13]. The maxillary interincisal midline should coincide with the facial midline, and when this is not possible, it should lie parallel to the facial midline [14]. Kokich et al. reported that a variation between the facial line and the maxillary interincisal midline limited to $4 \mathrm{~mm}$ is not perceptible to either patients or dental professionals [15], though other authors consider that a smaller difference proves evident. This is the case of Sadrhaghighi et al. [16], who recorded a deviation of the maxillary interincisal midline with respect to the facial midline of between 1 and 3 $\mathrm{mm}$. Pinho et al. [17] in turn found that orthodontists are able to detect any lack of coincidence of the two midlines, while prosthodontists detect no evident alterations until the difference reaches at least $2 \mathrm{~mm}$. Zhang et al. [18] found that the side to which the maxillary interincisal midline is deviated (right or left) resulted in no significant differences in terms of perception of the deviation. In contrast, an inclined midline would be more evident, and therefore less acceptable [19]. However, a midline deviation of over 2 $\mathrm{mm}$, an inclination of the midline of 3.5 degrees, and an inclination of the incisal plane of 2 degrees have been described as defining a scantly aesthetic smile in another study [20].

The arc of the smile can be defined as the relationship between the curve of the incisal margins of the upper incisors and canines and the curve of the lower lip in a posed smile, and may be consonant or non-consonant [12]. The curve of the upper lip can be divided into three categories according to the position of the corners of the mouth in relation to the center of the lower margin of the lip: upward, straight or downward [21]. The smile line in turn is classified as high if it exposes the entire clinical crown together with a continuous gingival band of variable size; medium if it exposes $75-100 \%$ of the clinical crown and only the interdental papilla; or low when the smile exposes less than $75 \%$ (three-quarters) of the clinical crown [22]. The shape of the maxillary central incisors is determined by their incisal-cervical height and maximum mesiodistal width. Marvouskoufis and Ritchie [23] reported that $86-90 \%$ of the studied population did not exhibit exactly the same dimensions in both contralateral teeth, while other authors found no statistically significant differences $[24,25]$, and any such differences were not relevant from the clinical perspective [3].

The present study was carried out to determine whether there are gender differences in a number of smile aesthetic parameters, with the purpose of facilitating the planning of multidisciplinary treatment. These parameters are coincidence of the maxillary interincisal midline with the facial midline, the arc of the smile, curve of the upper lip, line and width of the smile, and the shape of the upper central incisors. Our working hypothesis was that most of the population presents a maxillary midline centered with respect to the facial midline, a consonant arc of the smile, an upward curve of the upper lip, a medium smile line and ovoid teeth $[3,6,26]$.

\section{Methods}

In the present prospective study, photographs were obtained under resting and forced smiling conditions in 140 individuals with a mean age of $20.1 \pm 4.3$ years (range 18-30), at the Universidad Europea de Valencia (Valencia, Spain). The study was conducted in accordance with the Declaration of Helsinki, and was approved by the local Research Ethics Committee (Ref. CIPI/100/ 17).

All enrolled subjects were of Caucasian origin, with complete and fully erupted permanent dentition, and with no current or past orthodontic treatments. Before the start of the study, all individuals were fully informed on the nature of this study, read and signed a written consent form for inclusion, and for the analysis of the records obtained, that was approved by the University. Individuals with a history of orofacial trauma were excluded, as were those with anterior sector prostheses or dental implants, periodontal disease, incisal marginal wear, and caries with the loss of tooth material [4].

The photographs were obtained with a DSLR camera (Nikon, model D3100) using an 18-55 mm objective (Tokina) and a tripod (Canon Inc.) positioned at a distance of $40 \mathrm{~cm}$ from the study subject. The participants were positioned sitting in a chair placed $10 \mathrm{~cm}$ from the wall in order to avoid shadow effects, with the head relaxed and the gaze focused on an external point at eye level so that the Frankfort plane and the bipupillary line were parallel to the axis of the objective of the camera positioned in the same plane for obtaining the extraoral photographs [27]. The smile was photographed from the frontal position with the axis of the objective of the camera in the same plane as the occlusal plane. In obtaining the photographs, the authors always sought to maintain parallelism through the guiding reference lines in the visor of the digital camera, and a millimetered ruler was positioned on one side of the head of the patient to calibrate the real dimensions of the photographs on analyzing the images. In the frontal facial photographs, the focus point and center of the photograph were the intersection between the horizontal Frankfort line and the midline of the face, while for the intraoral photographs they were located between the incisal plane and the dental midline.

A single trained investigator (MM) recorded all the parameters. Adobe Photoshop CC2018 (Adobe Systems Incorporated Co.) and Adobe LightRoom 6 (Adobe Systems Incorporated Co.) were used by two investigators (PG and $\mathrm{MB}$ ) to evaluate the characteristics of the smile. The images 
were examined independently by each examiner, and the results of the evaluated features were subsequently compared. In the event of disagreement, the image was again evaluated jointly to reach consensus. The level of agreement between the two authors was assessed based on the Cohen kappa statistic. The maxillary interincisal midline [19] was classified as either centered or deviated in relation to the facial midline, determined by the line from nasion to filtrum. The arc of the smile in turn was classified as either consonant and non-consonant, while the curve of the upper lip was classified as upward, straight or downward [12, 22]. Depending on the amount of tooth and gingiva exposed on smiling, this line was defined as high, medium or low $[28,29]$. Smile width was determined according to the number of teeth exposed on smiling [30, 31]. The relationship between the shape and proportion of the central incisors (DP) was calculated using the formula DP\% = maximum width $(\mathrm{mm}) /$ length $(\mathrm{mm}) \times 100$, classifying the teeth as triangular, ovoid or square [32].

\section{Statistical analysis}

The data were entered on a spreadsheet for subsequent analysis using the SPSS version 15.0 statistical package. A descriptive study was made based on statistical frequency for each of the parameters in the global sample and stratified according to gender. Subject gender was defined as the fundamental independent variable of the study, with a view to determining the existence of sexual dimorphism associated to the mentioned parameters.

A bivariate analysis was carried out using the chi-squared test to assess the degree of association between the different parameters and patient gender, since it can be employed with data measurable on a nominal scale. Perfect coincidence between the observed and the expected frequencies received a value of 0 . In contrast, large discrepancies between the frequencies resulted in a large value of the statistic, with consequent rejection of the null hypothesis. Accordingly, the critical region was located at the upper range of the chisquared distribution with k-1 degrees of freedom. The Fisher exact test was used in those cases where the contingency tables presented many cells ( $>33 \%$ ) with low expected frequencies $(<5$ cases). This allowed us to determine whether two dichotomic variables are related. The Mann-Whitney Utest is a nonparametric test applied to two independent samples. It was used to contrast the homogeneity of distribution of a variable between two independent groups, such as smile line according to gender. The study sample presented a statistical power of $80 \%$ with a confidence level of $95 \%$ in detecting statistically significant differences between proportions 50 and 65\% in two groups (according to gender) using the chisquared test. The level of significance was $5 \%(\alpha=0.05)$. The sample size was calculated from the following formula: Potency $=1-\beta=F_{g l, l a m b d a, 1-\alpha}\left(\boldsymbol{\aleph}_{c r i t}^{2}\right)$, where: $\mathrm{df}=$ degrees of freedom, lambda (noncentrality parameter) $=\mathrm{w}^{2} \mathrm{n}, \mathrm{w}$ (effect size $)=\sqrt{\sum_{i=1}^{m} \frac{\left(p_{o i}-p_{1 i}\right)^{2}}{p_{o i}}}, \mathrm{p}_{0 \mathrm{i}}, \mathrm{p}_{1 \mathrm{i}}=$ the sample proportions, $\mathrm{n}=$ the sample size, $\alpha=$ critical probability level, $\boldsymbol{\aleph}_{\text {crit }}^{2}=$ the critical distribution value $\boldsymbol{\aleph}_{g l, 1-\alpha}^{2}$ and $\mathrm{F}=$ cumulative distribution function for $\boldsymbol{\kappa}^{2}$ with the noncentrality parameter lambda.

\section{Results}

Photographs corresponding to 140 individuals (70 males and 70 females) with a mean age of $20.1 \pm 4.3$ years were analyzed. Table 1 shows the statistical results referred to the associations between the study parameters and gender. None of the parameters showed significant differences in terms of gender. The kappa coefficient for interrater reliability was 0.81 .

\section{Maxillary interincisal midline versus facial midline}

In the great majority of the subjects $(94.3 \% ; n=132)$, the maxillary dental midline coincided with the facial midline, while $5.7 \%(n=8)$ showed deviation (Fig. 1) (Table 2).

\section{Arc of the smile}

Of the 140 individuals evaluated, $80 \%(n=112)$ presented a consonant arc of the smile, while the remaining $20 \%(n=28)$ showed a non-consonant arc. There were no statistically significant differences between males and females $(p=1)$ (Fig. 2) (Table 3).

\section{Curve of the upper lip}

A total of $47.1 \%$ of the patients $(n=66)$ had an upward lip curve, $41.4 \%(n=58)$ had a straight curve, and $11.4 \%$ $(n=16)$ presented a downward upper lip curve $(p=$ 0.315) (Fig. 3) (Table 4).

\section{Smile line}

Most of the patients $(84.3 \% ; n=118)$ presented a medium smile line, $8.6 \%(n=12)$ a low smile line, and $7.1 \%(n=10)$ a high smile line. According to gender,

Table 1 Association between different study parameters and gender. Results of Chi ${ }^{2}$ test, Fisher test (Fis) and Mann-Whitney (MW). Maxillary Interincisal mildilne (IML), facialmidline (FML), arch of the smile (ArS), curve of the lip (CL), smile line (SL), width of the smile (WS), shape of the teeth (Sh)

\begin{tabular}{ll}
\hline & $p$-value \\
\hline IML/FML & $0,614(\mathrm{Fis})$ \\
ArS & $1000\left(\mathrm{Chi}^{2}\right)$ \\
CL & $0,315\left(\mathrm{Chi}^{2}\right)$ \\
SL & $0,135(\mathrm{MW})$ \\
WS & $0,951\left(\mathrm{Chi}^{2}\right)$ \\
Sh & $0,379\left(\mathrm{Chi}^{2}\right)$ \\
\hline
\end{tabular}




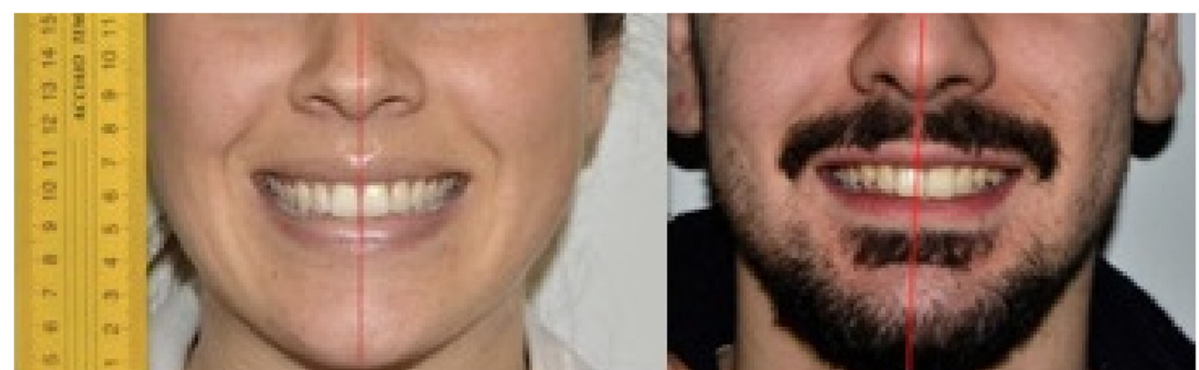

Fig. 1 Coincidence of the maxillary interincisal midline with the facial midline (left), and absence of coincidence (right)

females more often presented a high smile line compared with males ( $11.4 \%$ versus $2.9 \%$, respectively). In contrast, males showed a higher frequency of low smile lines $(11.4 \%$ versus $5.7 \%)(p=0.135)$ (Fig. 4) (Table 5).

\section{Width of the smile}

Of the 140 patients evaluated, 61.4\% $(n=86)$ showed tooth exposure to the second premolar, $20 \%(n=28)$ to the first molar, and $18.6 \%(n=26)$ to the first premolar $(p=0.951)$ (Fig. 5) (Table 6).

\section{Shape of the teeth}

A total of $62.9 \%$ of the subjects $(n=88)$ presented an oval tooth shape, $22.9 \%(n=32)$ a square shape, and $14.3 \%(n=20)$ a triangular tooth shape $(p=0.379)$ (Fig. 6) (Table 7).

\section{Discussion}

The present study was carried out to explore possible gender differences in certain aesthetic parameters, and their frequency in the population considered. Most of the patients were seen to have a maxillary interincisal midline coinciding with the facial midline, a consonant smile arc, and a medium smile line. The null hypothesis that there are no differences in these parameters on comparing them with other studies populations was therefore met.

Ethnicity and age are key conditioning factors of smile characteristics [22, 33], and for this reason they were clearly defined in our inclusion and exclusion criteria in order to secure a homogeneous sample of subjects. Our series showed a predominance of medium smile lines

Table 2 Frequency and percentage of the interincisal midline versus facial midline in the sample according to gender

\begin{tabular}{|c|c|c|c|c|c|c|}
\hline & \multicolumn{6}{|c|}{ GENDER } \\
\hline & \multicolumn{2}{|l|}{ Total } & \multicolumn{2}{|c|}{ Female } & \multicolumn{2}{|c|}{ Male } \\
\hline & $\mathrm{N}$ & $\%$ & $\mathrm{~N}$ & $\%$ & $\mathrm{~N}$ & $\%$ \\
\hline Total & 140 & $100,0 \%$ & 70 & $100,0 \%$ & 70 & $100,0 \%$ \\
\hline Centered & 132 & $94,3 \%$ & 68 & $97,1 \%$ & 64 & $91,4 \%$ \\
\hline Deviated & 8 & $5,7 \%$ & 2 & $2,9 \%$ & 6 & $8,6 \%$ \\
\hline
\end{tabular}

(84.3\%), in coincidence with the observations of other authors [19, 22, 31, 33].

The ideal smile line is that in which the maxillary interincisal midline is centered with respect to the facial midline, and the teeth are fully exposed along with about $1 \mathrm{~mm}$ of gingival tissue. Accordingly, a smile that exposes no more than $2-3 \mathrm{~mm}$ is regarded as aesthetically pleasant, while the exposure of over $3 \mathrm{~mm}$ of gingival tissue is regarded as scantly attractive by most patients [27]. From the perspective of orthodontists, Dindaroğlu et al. reported that the amount of tooth exposed in the smile is decisive for regarding a smile as aesthetically pleasant $(p=0.018)$ [9]. Del Monte et al. [34] found that there should be $0.4 \mathrm{~mm}$ of gingival display when smiling. Asymmetry during smiling could be considered clinically as a dental occlusal cant or maxillary skeletal asymmetry [10], and it is crucial to know the underlying cause

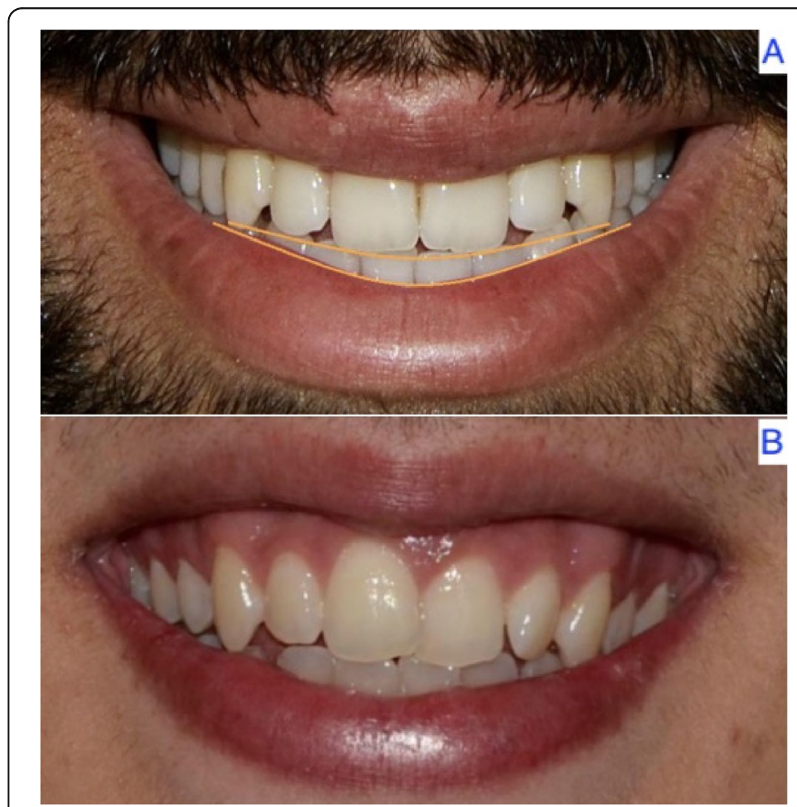

Fig. 2 Consonant (a) and non-consonant arc of the smile (b), determined by the upper incisal line and the internal surface of the lower lip 
Table 3 Frequency and percentage of the arc of the smile in the sample according to gender

\begin{tabular}{|c|c|c|c|c|c|c|}
\hline & \multicolumn{6}{|c|}{ GENDER } \\
\hline & \multicolumn{2}{|c|}{ Total } & \multicolumn{2}{|c|}{ Female } & \multicolumn{2}{|c|}{ Male } \\
\hline & $\mathrm{N}$ & $\%$ & $\mathrm{~N}$ & $\%$ & $\mathrm{~N}$ & $\%$ \\
\hline Total & 140 & $100,0 \%$ & 70 & $100,0 \%$ & 70 & $100,0 \%$ \\
\hline Centered & 112 & $80,0 \%$ & 56 & $80,0 \%$ & 56 & $80,0 \%$ \\
\hline Deviated & 28 & $20,0 \%$ & 14 & $20,0 \%$ & 14 & $20,0 \%$ \\
\hline
\end{tabular}

through careful diagnostic evaluation, in order to define the treatment best suited to each individual case.

In our sample, a high smile was more common among females than in males, while a low smile line was more prevalent among males - this being consistent with the data found in the literature [29, 33, 35]. In our study, $84.3 \%$ of the sample presented a medium smile line, $8.6 \%$ a low smile line and $7.1 \%$ a high smile line. The height of the smile line decreases with age as a result of the loss of supporting tissues. A high smile line poses a challenge for aesthetic restoration of the anterior sector [28], and a combined multidisciplinary management approach may be required $[36,37]$.

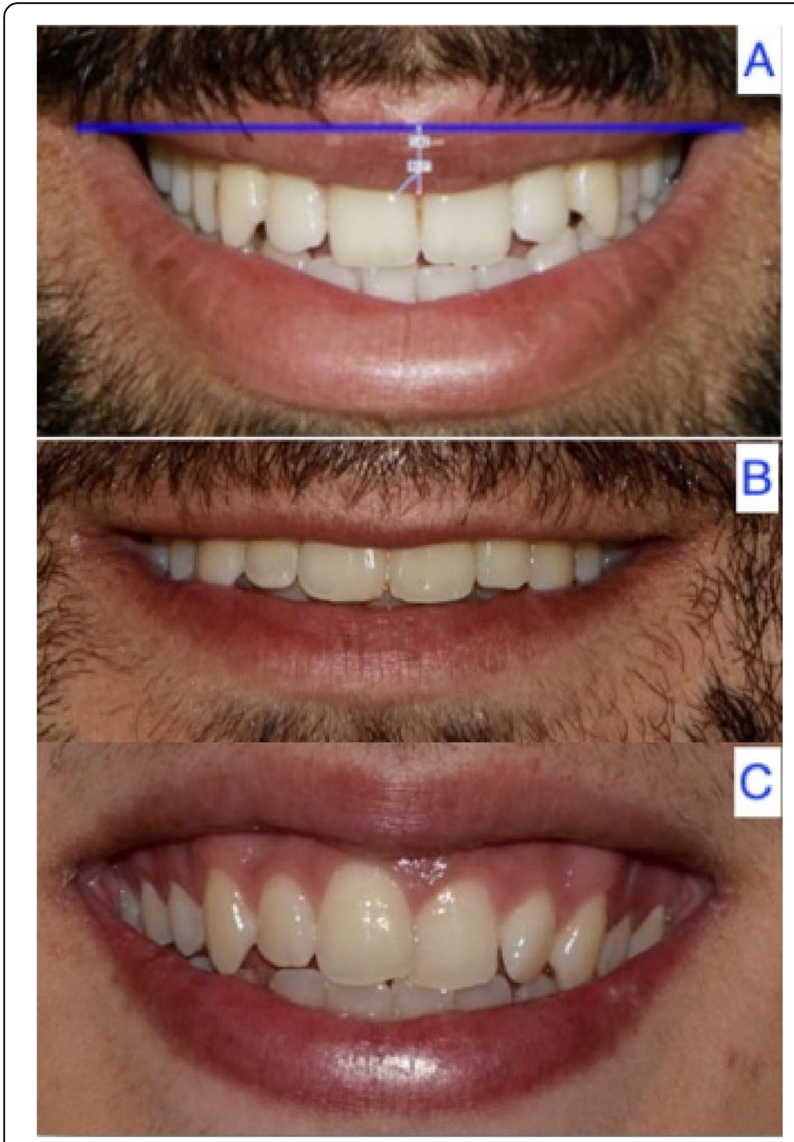

Fig. 3 Upward (a), straight (b) and downward curve of the upper lip (c)
Table 4 Curve of the upper lip in the sample according to gender

\begin{tabular}{|c|c|c|c|c|c|c|}
\hline & \multicolumn{6}{|c|}{ GENDER } \\
\hline & \multicolumn{2}{|c|}{ Total } & \multicolumn{2}{|c|}{ Female } & \multicolumn{2}{|c|}{ Male } \\
\hline & $\bar{N}$ & $\%$ & $\bar{N}$ & $\%$ & $\overline{\mathrm{N}}$ & $\%$ \\
\hline Total & 140 & $100,0 \%$ & 70 & $100,0 \%$ & 70 & $100,0 \%$ \\
\hline Upward & 66 & $47,1 \%$ & 36 & $51,4 \%$ & 30 & $42,9 \%$ \\
\hline Straight & 58 & $41,4 \%$ & 30 & $42,9 \%$ & 28 & $40,0 \%$ \\
\hline Downward & 16 & $11,4 \%$ & 4 & $5,7 \%$ & 12 & 17,1 \\
\hline
\end{tabular}

With regard to the arc of the smile, our results show a greater frequency of cases with a consonant arc (80\%). This is in contradiction to the results published by Maulik and Nanda [31] - the reason probably being the use of different inclusion criteria, since the mentioned authors did not specify the ethnic composition of their sample. However, our findings do coincide with those of other authors $[19,22,33]$. A parallel smile arc is the most aesthetic and attractive presentation, followed by a straight arc, while an inverted arc is considered to be scantly aesthetic [33]. Lombardi and Desai et al. reported that the arc of the smile is related to the age of the individual $[22,38]$. In youth, the central incisors are more prominent, generating

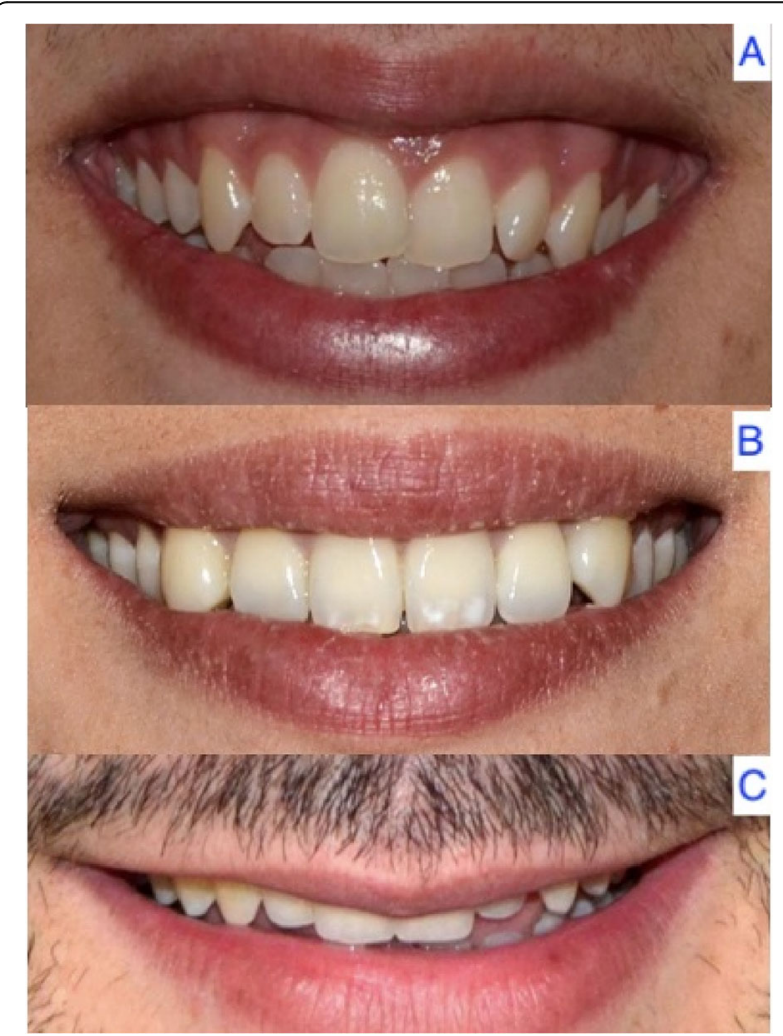

Fig. 4 High (a), medium (b) and low smile line (c) 
Table 5 Smile line in the sample according to gender

\begin{tabular}{|c|c|c|c|c|c|c|}
\hline & \multicolumn{6}{|c|}{ GENDER } \\
\hline & \multicolumn{2}{|l|}{ Total } & \multicolumn{2}{|c|}{ Female } & \multicolumn{2}{|c|}{ Male } \\
\hline & $\bar{N}$ & $\%$ & $\bar{N}$ & $\%$ & $\bar{N}$ & $\%$ \\
\hline Total & 140 & $100,0 \%$ & 70 & $100,0 \%$ & 70 & $100,0 \%$ \\
\hline Medium & 118 & $84,3 \%$ & 58 & $82,9 \%$ & 60 & $85,7 \%$ \\
\hline Low & 12 & $8,6 \%$ & 4 & $5,7 \%$ & 8 & $11,4 \%$ \\
\hline High & 10 & $7,1 \%$ & 8 & $11,4 \%$ & 2 & $2,9 \%$ \\
\hline
\end{tabular}

a curve that is parallel and consonant with the lower lip, while in older individuals the curve tends to straighten as a result of wear.

The facial midline and maxillary interincisal midline were seen to be coincident in $94.3 \%$ of the studied subjects. These results are comparable to those of other publications [29, 39]. A coincident midline is the most prevalent presentation in nature and must be respected in prosthetic dental treatment in order to ensure an aesthetic outcome [33, 40]. Silva et al. [7] found the threshold for perceiving a deviation of the maxillary interincisal midline with respect to the facial midline to be $2 \mathrm{~mm}$, in coincidence with the observations of other authors $[16,18]$. Orthodontists are able to detect alterations of the maxillary

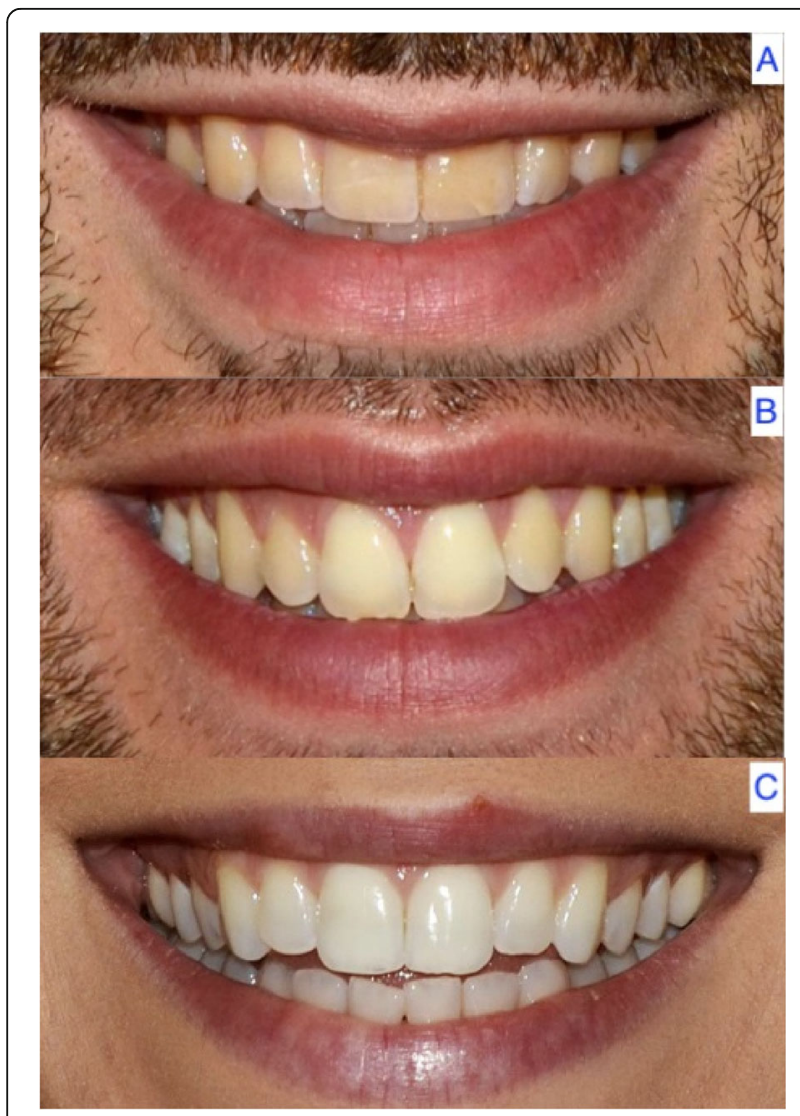

Fig. 5 Smile width with exposure to the first premolar (a), second premolar (b) and first molar (c)
Table 6 Width of the smile in the sample according to gender

\begin{tabular}{|c|c|c|c|c|c|c|}
\hline & \multicolumn{6}{|c|}{ GENDER } \\
\hline & \multicolumn{2}{|c|}{ Total } & \multicolumn{2}{|c|}{ Female } & \multicolumn{2}{|c|}{ Male } \\
\hline & $\bar{N}$ & $\%$ & $\bar{N}$ & $\%$ & $\bar{N}$ & $\%$ \\
\hline Total & 140 & $100,0 \%$ & 70 & $100,0 \%$ & 70 & $100,0 \%$ \\
\hline Second premolar & 86 & $61,4 \%$ & 44 & $62,9 \%$ & 42 & $60,0 \%$ \\
\hline First molar & 28 & $20,0 \%$ & 14 & $20,0 \%$ & 14 & $20,0 \%$ \\
\hline First premolar & 26 & $18,6 \%$ & 12 & $17,1 \%$ & 14 & $20,0 \%$ \\
\hline
\end{tabular}

interincisal midline with respect to the facial midline of as small as $1 \mathrm{~mm}$. Parrini et al. [41] conducted a systematic review of smile perception among laypersons, and found a mean deviation of $2.38 \mathrm{~mm}$ to be acceptable.

In those cases where a coincident midline is not possible, the midline between the central incisors must be parallel to the facial midline [29]. The greater the discrepancy between these lines, the greater the asymmetry of the patient smile, and this proves evident even for an inexpert observer [42]. An incorrect inclination of the maxillary interincisal midline can be immediately recognized by any observer as scantly aesthetic, being less attractive than a lateral deviation of the maxillary interincisal midline with respect to the facial midline [13]. Thomas et al. found angulation of the maxillary interincisal midline to have a tolerance limits of $10 \pm 6$ degrees in laypersons [43].

With regard to tooth shape, our global sample showed a predominance of oval shaped teeth $(62.9 \%)$, in concordance with the observations of other authors [44, 45]. It is

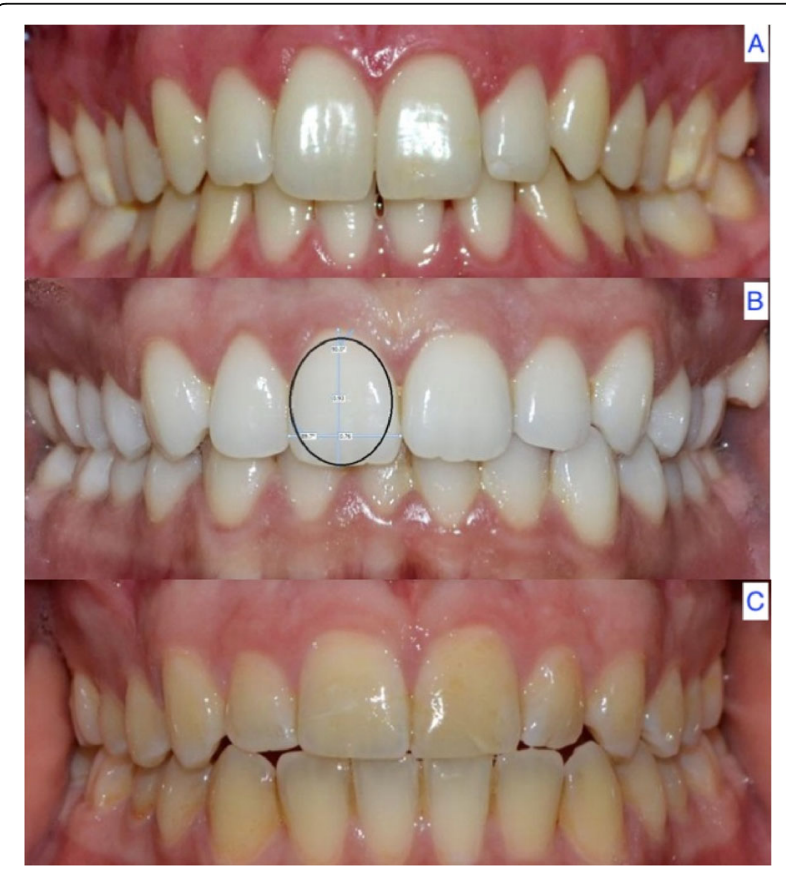

Fig. 6 Tooth shapes: triangular (a), oval (b) and square (c) 
Table 7 Frequency and percentage of the tooth shape according to gender

\begin{tabular}{|c|c|c|c|c|c|c|}
\hline & \multicolumn{6}{|c|}{ GENDER } \\
\hline & \multicolumn{2}{|c|}{ Total } & \multicolumn{2}{|c|}{ Female } & \multicolumn{2}{|c|}{ Male } \\
\hline & $\mathrm{N}$ & $\%$ & $\mathrm{~N}$ & $\%$ & $N$ & $\%$ \\
\hline Total & 140 & $100,0 \%$ & 70 & $100,0 \%$ & 70 & $100,0 \%$ \\
\hline Ovoid & 88 & $62,9 \%$ & 46 & $65,7 \%$ & 42 & $60,0 \%$ \\
\hline Square & 32 & $22,9 \%$ & 18 & $25,7 \%$ & 14 & $20,0 \%$ \\
\hline Triangular & 20 & $14,3 \%$ & 6 & $8,6 \%$ & 14 & $20,0 \%$ \\
\hline
\end{tabular}

important to know the aesthetic preferences of the population when designing rehabilitation. Thus, according to Alvarez-Alvarez et al. [46], both dentists and laypersons consider the proportion of $85 \%$ for the central incisor and $80 \%$ for the lateral incisor and canine to be the most aesthetic scenario.

The bivariate analysis revealed no statistically significant differences according to gender, in coincidence with data found in the literature [33]. However, Brunetto et al. did record a significant gender difference in that males tended to show a more triangular dental shape versus a more square shape in females [45]. This significant gender difference can probably be explained by the fact that the mentioned authors analyzed 433 Brazilian patients between 15 and 30 years of age, i.e., their sample characteristics were different from our own. In the study published by Anderson et al. [47], square-round incisors were preferred for males by all the groups surveyed ( $\boldsymbol{p} \leq$ 0.042 ). In contrast, the shape regarded by orthodontist as most aesthetically pleasing for females was round and square-round incisors $(\boldsymbol{p}<0.01)$, versus round incisors in the opinion of restorative dentists $(\boldsymbol{p} \leq 0.03)$. The principles of visagism hold that female tooth shape is often more ovoid and delicate, while males are characterized by a more square tooth shape associated with virility [48].

In view of the controversial results, the selection of tooth shape based on gender lacks adequate scientific support and reliability. In the case of doubt, Nold et al. recommend selecting central incisors with an oval shape, as there is a greater probability of correlation with the natural teeth than when other tooth shapes are considered, independently of patient gender [33].

With regard to smile width, our results indicate a greater prevalence of exposure to the second premolar (61.4\%), in agreement with the observations of other authors [29, 31]. However, Tjan and Miller [19] found the highest prevalence to correspond to exposure to the first premolar (48.6\%). A possible explanation for this discrepancy is that these authors analyzed a sample (North Americans aged between 20 and 30 years) different from our own. Moreover, they found that only $4 \%$ of the subjects exposed their upper first molars when smiling - this finding being clearly different from the $20 \%$ recorded in our series. Aesthetic restoration of the visible posterior teeth may prove necessary in order to secure a harmonious outcome [49]. This is an important factor when planning anterior restorations, since consideration is required of both smile width and the number of teeth exposed. Variations in smile width allow for a broad range of situations considered to be aesthetically agreeable [50].

The results obtained in relation to the curve of the upper lip indicate a predominance of high lip curves (47\%). Similar findings have been made in other studies such as that published by Hulsey [51], though in contrast Nold et al. [33] and Liang et al. [21] recorded a greater frequency of straightened curves. The differences with respect to Liang et al. [21] are probably due to the fact that their sample consisted of Chinese individuals, and ethnicity may play an important role in this regard.

\section{Conclusions}

The different aesthetic parameters must be efficiently integrated in clinical practice, since a range of disciplines are implicated in patient management (restoration, prostheses, orthodontics, periodontics). No significant gender differences were observed in relation to the parameters studied, with the exception of the smile line, which was found to be higher in females than in males. The population studied has a maxillary interincisal midline centered with the facial midline, a consonant arc of the smile, an upward lip curve, a medium smile line, with exposure to the second premolar, and an oval tooth shape. The present study may serve as a guide for dental professionals in orthodontics, restorative dentistry or prosthetic rehabilitation, among other fields.

\section{Abbreviations}

ArS: Arch of the smile; CL: Curve of the lip; Fis: Fisher test; FML: Facialmidline; IML: Maxillary Interincisal mildilne; MW: Mann-Whitney test; Sh: Shape of the teeth; SL: Smile line; WS: Width of the smile

\section{Acknowledgements \\ Not Applicable}

\section{Authors' contributions}

M.M. contributed to the design of the study, reviewed and analysed the study data. M.B. and P.G. contributed to data collection and analysis. F. A and T. C contributed to the data analysis. JAA and JMMG contributed to the design of the study, data interpretation and drafted the manuscript. All authors contributed to preparation and approval of the final version of the manuscript.

\section{Funding}

The present study was not funded, nor supported by any grant. Nothing was provided by third-parts or private companies: therefore, the authors have no conflict of interest related to the present work.

Availability of data and materials

The datasets used in this study are available from the corresponding author on reasonable request. 


\section{Ethics approval and consent to participate}

All participants provided written informed consent. The study was conducted in accordance with the Declaration of Helsinki, and was approved by the local Research Ethics Committee (Ref. CIPI/100/17) at the Universidad Europea de Valencia (Valencia, Spain).

\section{Consent for publication}

All participants provided written consent for the publication of potentially identifying images.

\section{Competing interests}

The authors declare that they have no competing interests.

\begin{abstract}
Author details
${ }^{1}$ Valencia University Medical and Dental School, University of Valencia, Valencia, Spain. ${ }^{2}$ Department of Dentistry, Universidad Europea de Valencia. Faculty of Health Sciences, Valencia, Spain. ${ }^{3}$ Dentist, Public Dental Health Service, Conselleria de Sanitat Universal i Salut Pública, Generalitat Valenciana, Valencia, Spain. ${ }^{4}$ Department of Surgery and Medical-Surgical Specialities, Area of Orthodontics, University Medical and Dental School. University of Oviedo (Spain). Instituto Asturiano de Odontologia, Oviedo, Spain. ${ }^{5}$ Department of Medicine and Oral Surgery, Faculty of Dentistry, Complutense University of Madrid, Madrid, Spain.
\end{abstract}

Received: 24 June 2019 Accepted: 31 January 2020 Published online: 06 February 2020

\section{References}

1. Rodrigues CD, Magnani R, Machado MS, Oliveira OB. The perception of smile attractiveness. Angle Orthod. 2009;79:634-9.

2. Machado AW. 10 commandments of smile esthetics. Dental Press J Orthod. 2014;19:136-57.

3. Melo M, Ata-Ali F, Huertas J, Cobo T, Shibli JA, Galindo-Moreno P, Ata-Ali J. Revisiting the maxillary teeth in 384 subjects reveals a deviation from the classical aesthetic dimensions. Sci Rep. 2019;9:730. https://doi.org/10.1038/ s41598-018-36770-w.

4. Hasanreisoglu U, Berksun S, Aras K, Arslan I. An analysis of maxillary anterior teeth: facial and dental proportions. J Prosthet Dent. 2005;94:530-8.

5. Shetty S, Pitti V, Satish Babu C, Surendra Kumar G, Jnanadev K. To evaluate the validity of recurring esthetic dental proportion in natural dentition. J Conserv Dent. 2011;14:314-7.

6. Morley J, Eubank J. Macroesthetic elements of smile design. J Am Dent Assoc. 2001;132:39-45.

7. Silva BP, Jiménez-Castellanos E, Martinez-de-Fuentes R, Greenberg JR, Chu S Laypersons' perception of facial and dental asymmetries. Int J Periodontics Restorative Dent. 2013;33:e162-71.

8. Walder JF, Freeman K, Lipp MJ, Nicolay OF, Cisneros GJ. Photographic and videographic assessment of the smile: objective and subjective evaluation of posed and sponta- neous smiles. Am J Orthod Dentofac Orthop. 2013; 1446:793-801.

9. Dindaroğlu F, Ertan Erdinç AM, Doğan S. Perception of smile esthetics by orthodontists and laypersons: full face and a localized view of the social and spontaneous smiles. Turk J Orthod. 2016;29:59-68.

10. Duran GS, Dindaroğlu F, Görgülü S. Three-dimensional evaluation of social smile symmetry. Angle Orthod. 2017;87:96-103.

11. Ackerman $J \mathrm{~L}$, Ackerman MB, Brensinger CM, Landis JR. A morphometric analysis of the posed smile. Clin Orthod Res. 1998;1:2-11.

12. Sarver $\mathrm{D}$. The importance of incisor positioning in the esthetic smile: the smile arc. Am J Orthod Dentofac Orthop. 2001;120:98-111.

13. Miller $E$, Bodden W, Jamison $H$. A study of the relationship of the dental midline to the facial median line. J Prosthet Dent. 1979;41:657-60.

14. Latta $\mathrm{GH}$. The midline and its relation to anatomic landmarks in the edentulous patient. J Prosthet Dent. 1988;59:681-3.

15. Kokich VO, Kiyak HA, Shapiro PA. Comparing the perception of dentists and lay people to altered dental esthetics. J Esthet Dent. 1999;11:311-24.

16. Sadrhaghighi H, Zarghami A, Sadrhaghighi S, Eskandarinezhad M. Esthetic perception of smile components by orthodontists, general dentists, dental students, artists, and laypersons. J Investig Clin Dent. 2017;8:e12235.

17. Pinho S, Ciriaco C, Faber J, Lenza MA. Impact of dental asymmetries on the perception of smile esthetics. Am J Orthod Dentofac Orthop. 2007; 132:748-53.
18. Zhang YF, Xiao L, Li J, Peng YR, Zhao Z. Young people's esthetic perception of dental midline deviation. Angle Orthod. 2010;80:515-20.

19. Tjan AH, Miller GD. Some esthetic factors in a smile. J Prosthet Dent. 1984; 51:24-8.

20. Pereira Da Silva B, Jiménez-Castellanos E, Martínez de Fuentes R, Greenberg JR, Chu S. Laypersons' perception of facial and dental asymmetries. Int J Periodont Res. 2013;33:163-71.

21. Liang LZ, Hu WJ, Zhang YL, Chung KH. Analysis of dynamic smile and upper lip curvature in young Chinese. Int J Oral Sci. 2013;5:49-53.

22. Desai S, Upadhyay M, Nanda R. Dynamic smile analysis: changes with age. Am J Orthod Dentofacial Orthop. 2009;136:310.e1-10.

23. Mavroskoufis F, Ritchie GM. Variation in size and form between left and right maxillary central incisor teeth. J Prosthet Dent. 1980;43:254-7.

24. Sah SK, Zhang HD, Chang T, Dhungana M, Acharya L, Chen LL. Ding YM maxillary anterior teeth dimensions and proportions in a central mainland chinese population. Chin J Dent Res. 2014;17:117-24.

25. Gran SM, Lewis AB, Kerewsky RS. Sex difference in tooth size. J Dent Res. 1964;43:306-15.

26. Jiménez-Castellanos E, Orozco-Varo A, Arroyo-Cruz G, Iglesias-Linares A. Prevalence of alterations in the characteristics of smile symmetry in an adult population from southern Europe. J Prosthet Dent. 2016;115:736-40.

27. Calçada D, Correia A, Araújo F. Anthropometric analysis of anterior maxillary teeth with digital photography — a study in a Portuguese sample. Int J Esthet Dent. 2014;9:370-80.

28. Zarone F, Leone R, Ferrari M, Sorrentino R. Treatment Concept for a Patient with a High Smile Line and Gingival Pigmentation: A Case Report. Int J Periodontics Restorative Dent. 2017;37:e142-8. https://doi.org/10.11607/prd.2833.

29. Al-Johany SS, Alqahtani AS, Alqahtani FY, Alzahrani AH. Evaluation of different esthetic smile criteria. Int J Prosthodont. 2011;24:64-70.

30. Sabri R. The eight components of a balanced smile. J Clin Orthod. 2005;39: 155-67.

31. Maulik C, Nanda R. Dynamic smile analysis in young adults. Am J Orthod Dentofac Orthop. 2007;132:307-15.

32. Weber B, Fuentes R, García N, Cantin M. Relationships between shape and proportion of the maxillary central incisor with facial measurements, dental and facial midline in adults. Int J Morphol. 2014;32:1101-7.

33. Nold SL, Horvath SD, Stampf S, Blatz MB. Analysis of select facial and dental esthetic parameters. Int J Periodontics Restorative Dent. 2014;34:622-9.

34. Del Monte S, Afrashtehfar KI, Emami E, Nader SA, Tamimi F. Lay preferences for dentogingival esthetic parameters: a systematic review. J Prosthet Dent. 2017;118:717-24.

35. Peck D, Peck L. Some vertical lineaments of lip position. Am J Orthop Dentofacial Orthop. 1992;101:519-24.

36. Wise RJ, Chen CY, Kim DM. Treatment of Physiologic Gingival Pigmentation with Surgical Blade: A 25-Year Follow-up. Int J Periodontics Restorative Dent. 2018;38:s45-8. https://doi.org/10.11607/prd.3701.

37. Kolte AP, Kolte RA, Ahuja C. Assessment of gingival zenith position and its level relative to age and gender in maxillary anterior teeth. Quintessence Int. 2018;49:761-8. https://doi.org/10.3290/j.qi.a41009.

38. Lombardi RE. The principles of visual perception and their clinical application to denture esthetics. J Prosthet Dent. 1973;29:358-82.

39. Owens EG, Goodacre CJ, Loh PL, Hanke G, Okamura M, Jo KH, Muñoz CA, Naylor WP. A multicenter interracial study of facial appearance. Part 1: a comparison of extraoral parameters. Int J Prosthodont. 2002;15:273-82.

40. Alhammadi MS, Halboub E, Al-Mashraqi AA, Al-Homoud M, Wafi S, Zakari A, Mashali W. Perception of facial, dental and smile esthetics by dental students. J Esthet Restor Dent. 2018;30:415-26. https://doi.org/10. $1111 /$ jerd.12405.

41. Parrini S, Rossini G, Castroflorio T, Fortini A, Deregibus A, Debernardi C. Laypeople's perceptions of frontal smile esthetics: a systematic review. Am J Orthod Dentofac Orthop. 2016;150:740-50.

42. Johnston CD, Burden DJ, Stevenson MR. The influence of dental to facial midline discrepancies on dental attractiveness ratings. Eur J Orthod. 1999;21: 517-22.

43. Thomas $\mathrm{J}$, Hayes $\mathrm{C}$, Zawaideh S. The effect of axial midline angulation on dental esthetics. Angle Orthod. 2003;73:359-64.

44. Wolfart S, Menzel H, Kern M. Inability to relate tooth forms to face shape and gender. Eur J Oral Sci. 2004;112:471-6.

45. Brunetto J, Becker MM, Volpato CA. Gender differences in the form of maxillary central incisors analyzed using auto-CAD software. J Prosthet Dent. 2011;106:95-101. 
46. Álvarez-Álvarez L, Orozco-Varo A, Arroyo-Cruz G, Jimenez-Castellanos E. Width/length ratio in maxillary anterior teeth. Comparative study of esthetic preferences among professionals and laypersons. J Prosthodont. 2019;28: 416-20.

47. Anderson KM, Behrents RG, McKinney T, Buschang PH. Tooth shape preferences in an esthetic smile. Am J Orthod Dentofac Orthop. 2005;128: 458-65.

48. Frush JP, Fisher RD. How dentogenic restorations interpret the sex factor. J Prosthet Dent. 1956;6:160-72.

49. Afify A, Haney S. Management of Challenging Esthetic Anterior Cases with limited restorative space: a clinical report. J Prosthodont. 2018;27:593-7. https://doi.org/10.1111/jopr.12750.

50. Zhang K, Huang L, Yang L, Xu L, Xue C, Xiang Z, Zhao M, Li S, Bai Y, Bai D. Effects of transverse relationships between maxillary arch, mouth, and face on smile esthetics. Angle Orthod. 2016;86:135-41. https://doi.org/10.2319/ 101514.1.

51. Hulsey CM. An esthetic evaluation of lip-teeth relationship present in the smile. Am J Orthod. 1970;57:132-44.

\section{Publisher's Note}

Springer Nature remains neutral with regard to jurisdictional claims in published maps and institutional affiliations.

Ready to submit your research? Choose BMC and benefit from:

- fast, convenient online submission

- thorough peer review by experienced researchers in your field

- rapid publication on acceptance

- support for research data, including large and complex data types

- gold Open Access which fosters wider collaboration and increased citations

- maximum visibility for your research: over $100 \mathrm{M}$ website views per year

At BMC, research is always in progress.

Learn more biomedcentral.com/submissions 